\title{
Production of net-shape static parts by direct HIPing of nickel base superalloy prealloyed powders
}

\author{
Gérard Raisson ${ }^{1,}$, Jean-Yves Guédou ${ }^{2, ~ b}$, Didier Guichard ${ }^{3,}$, \\ Jean-Marc Rongvaux ${ }^{2, d}$ \\ ${ }^{1}$ Aubert \& Duval - La Pardieu - 63063 Clermont-Ferrand (France) \\ 2 SNECMA - Villaroche - 77550 Moissy Cramayel (France) \\ ${ }^{3}$ SNECMA - BP802 - 27808 Vernon (France) \\ a gerard.raisson@eramet-aubertduval.com, ${ }^{b}$ jean-yves.guedou@snecma.fr, \\ c didier.guichard@snecma.fr, ${ }^{d}$ jean-marc.rongvaux@snecma.fr
}

\begin{abstract}
Key words : Powder metallurgy - Nickel base superalloy - Hot Isostatic Pressing (HIP) Isoprec®
\end{abstract}

\begin{abstract}
In order to reduce costs and increase the operating temperatures in aero-turboengines and space propulsion systems, net-shape or near net-shape production processes have been developed for static parts through HIPing (Hot Isostatic Pressing) of nickel base superalloys prealloyed powders. The presented results hereafter are related to the manufacturing processes and the mechanical properties (tensile, creep and LCF) characterisation. The effects of net shape surfaces and of surface conditioning have been investigated too. Examples of actual parts (CFM56 turbine casing and Vulcain rocket engine gas generator) illustrate the presentation. This study has confirmed the interest of this production route and future potential for development.
\end{abstract}

\section{Introduction}

Powder Metallurgy (PM) of superalloys was initially developed in the 1970's to overcome ingot solidification segregation problems in nickel base alloys containing high levels of hardening elements. The material consolidation was obtained by implementing as-HIPed (Hot Isostatic Pressing) parts which led also to an increase in material resistance. For rotating parts whose shape is rather simple, cleanliness problems have led to a more complex route involving extrusion + isothermal forging which has been developed in Europe and USA in the mid 1970's.

For static parts, the as-HIP route is industrially implemented for simple geometries such as rings (helicopter turbine containment rings for example). Mechanical properties can be similar to those of extruded + forged products $[1,2]$. A consortium between several French companies, institutes and laboratories has developed a process named Isoprec $\mathbb{R}$ [2] in order to accurately control the geometry of net-shape parts which is definitely an issue for complex shape applications needing precise specifications [3]. The extension to larger or more intricately shaped parts requires specific techniques for geometry control of HIPed parts.

Two kinds of parts have been studied:

- very large parts with a rather simple geometry

- smaller parts with intricate geometries

In both cases, the challenges versus conventional routes are to enable to use a stronger material compared to the basic one and also to reduce raw material input and associated machining costs.

After a presentation of the method used for geometry control, the mechanical properties will be exposed and more particularly the effects of surface condition (as-decanned or as-machined).

\section{Control of the geometry}

The schematic production route is shown in figure 1 and the principles of designing and sizing the tooling devices are given in [2]. For net-shape parts, modelling is usually not precise enough to get directly the right part satisfying the dimensional specifications. So iterative operations are generally 


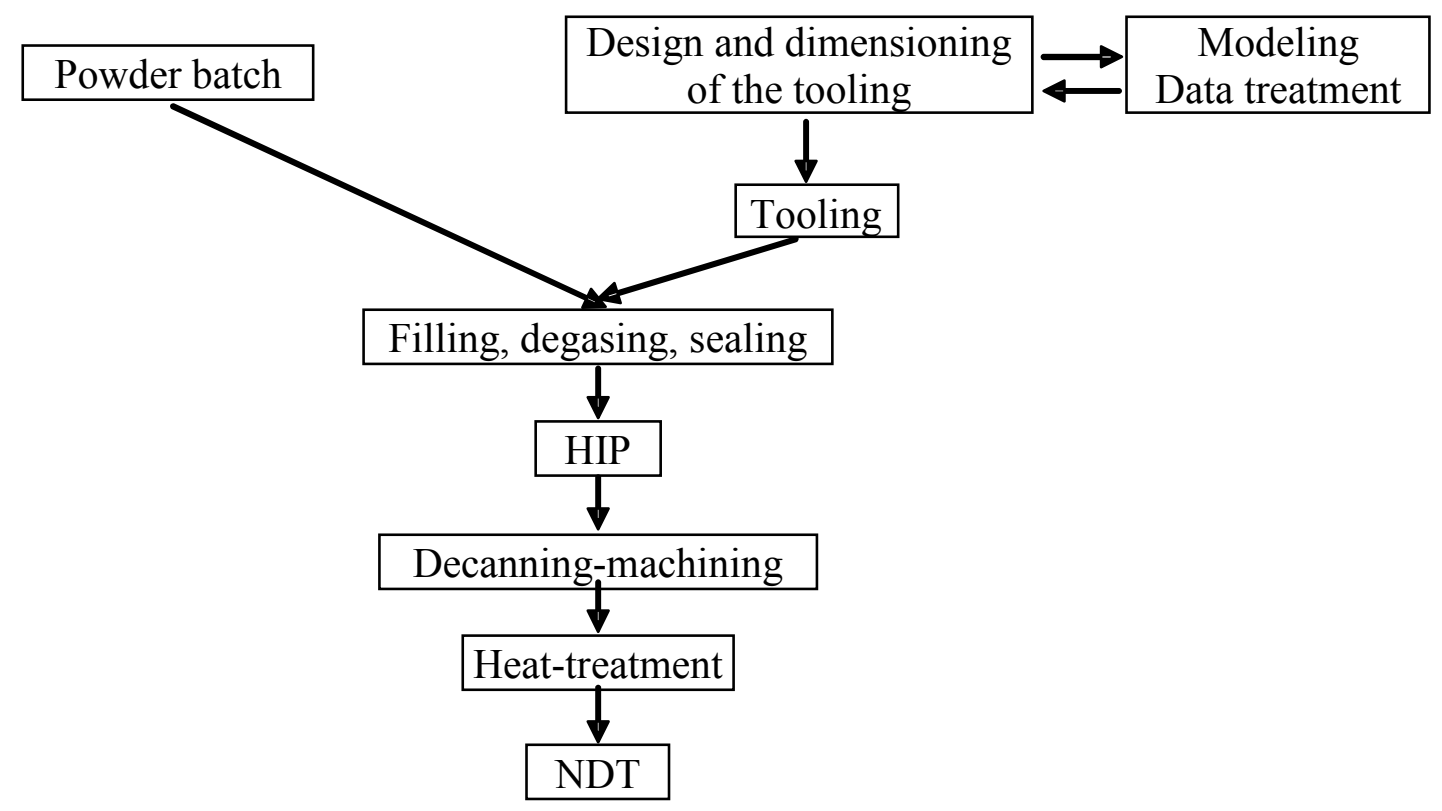

Figure 1: Production route (NDT: Non Destructive Testing)

needed. A method to process the data was developed and allowed to fulfil the objective target for the second part.

Quite different shapes can be produced in different materials (steels, titanium alloys...) as far as the dimensions or complexity are concerned.

For nickel base superalloys, two parts have been studied:

- Turbine casing in SYP3 (Astroloy type grade) for CFM56-5 engine:

The objective of using Isoprec ${ }^{\circledR}$ technology for that part was to increase the allowable temperature through replacing Waspaloy or 718 alloy by a more refractory grade elaborated through PM route. Another objective was to reduce material consumption in comparison with the conventional ring rolling process. The final shape being rather easy to machine, it was chosen to produce a near net shape part.

Figure 2 shows the delivered blank. The weight of used powder is $40 \mathrm{~kg}$, the weight of the delivered part is $32 \mathrm{~kg}$ and the final weight of the component is $18 \mathrm{~kg}$.

- Vulcain gas generator for Ariane rocket engine

Isoprec@ process has been first used for titanium alloy components in rocket engine parts (impellers in pumps) [4] and later for hotter parts. The gas generator application in SYP3 (Astroloy), with the target of a final machining only on flanges, bosses and fastening system, is much more ambitious. The main advantage is to enable to implement Astroloy, a more temperature resistant grade than the used Waspaloy which offers also a better strength in hydrogen environment.

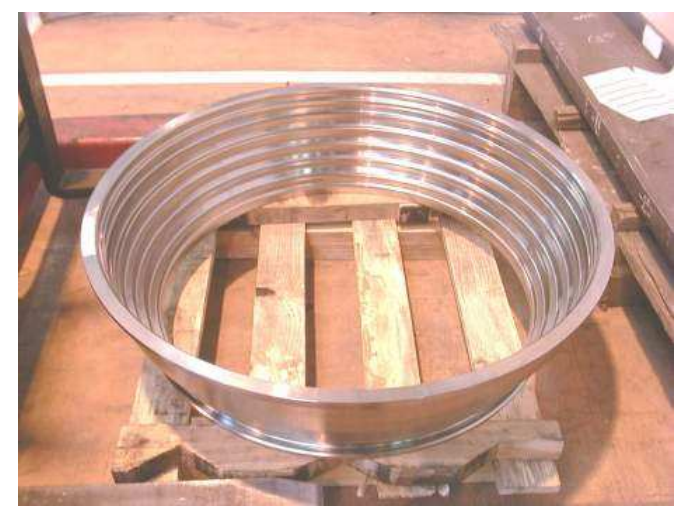

Figure 2: CFM56-5 turbine casing (diameter $1075 \mathrm{~mm}$ )

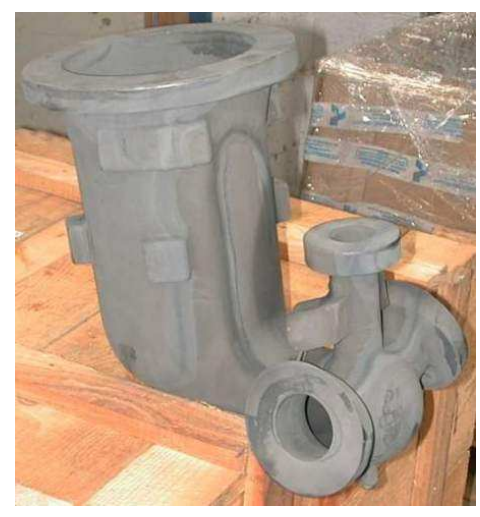

Figure 3: Vulcain Gas Generator as decanned by acid leaching 


\section{Metallurgical characterisations}

In as-HIPed conditions, mechanical properties of superalloys are very similar to those obtained on extruded + forged products $[1,2]$. Numerous specimens have been cut out from a turbine casing for metallurgical investigations and mechanical characterisation in final heat-treated conditions. The following conditions have been applied to the part:

- Sieving $125 \mu \mathrm{m}(-115 \mathrm{mesh})$

- HIPping: $1160^{\circ} \mathrm{C}, 100 \mathrm{MPa}$ for $4 \mathrm{~h}$

- Heat treatment: $1115^{\circ} \mathrm{C}-4 \mathrm{~h} \mathrm{AC}$ at $50-70^{\circ} \mathrm{C} / \mathrm{min}+760^{\circ} \mathrm{C}-8 \mathrm{~h} \mathrm{AC}+650^{\circ} \mathrm{C}-24 \mathrm{~h} \mathrm{AC}$ (AC: air cooling)

The duplex microstructure shown on figure 4 is typical of an as-HIPed material with fine grains (ASTM 9) combined with coarser ones (ASTM 5 to 6).

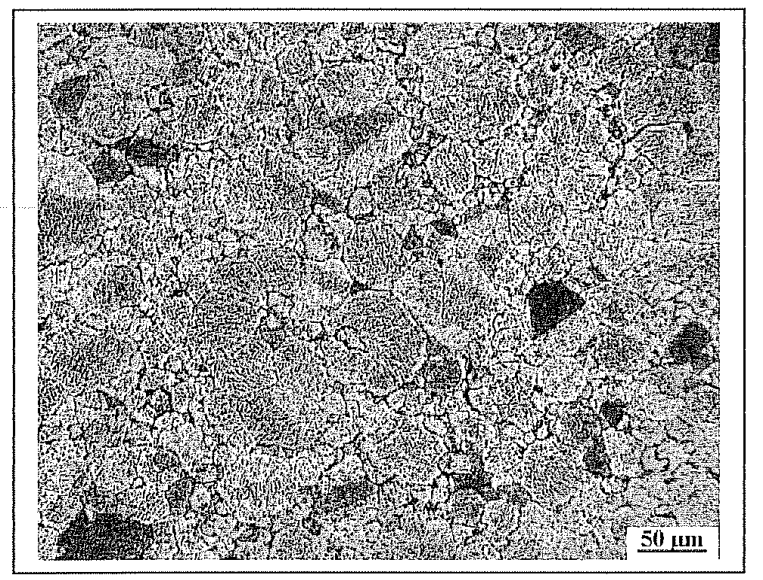

Figure 4: Microstructure of Heat Treated Material

\section{Surface characterisation}

Figure 5 shows the typical microstructure of net shape surface after acid leaching to eliminate the low carbon steel can, which reveals a diffusion bonding mechanism with the superalloy.

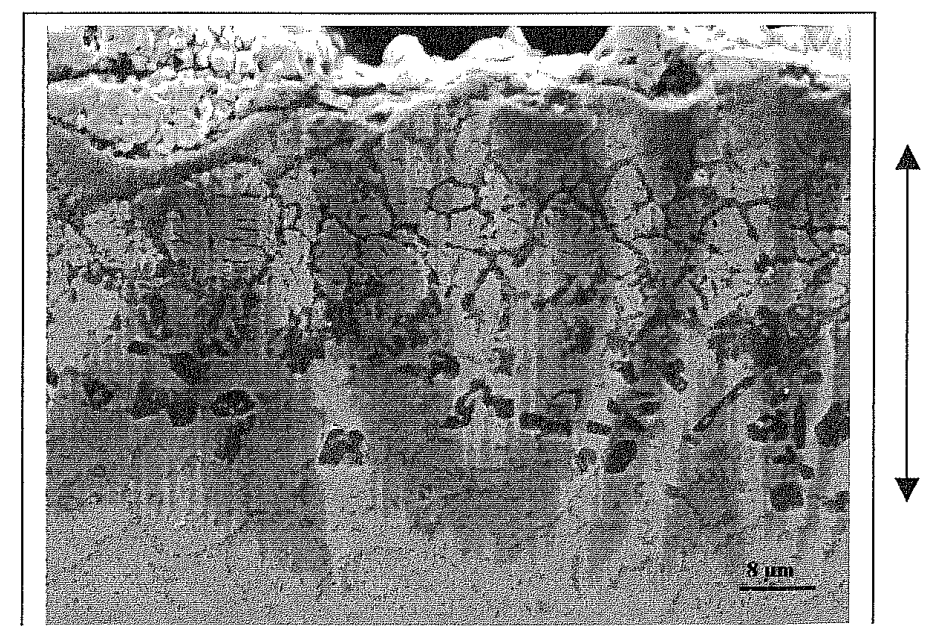

Figure 5: Diffusion layer of net shape as acid leached

A $60 \mu \mathrm{m}$ layer with depletion of $\gamma$ 'precipitates, carbide precipitation and locally some cracks is observed. The roughness is related to the particle size distribution through soft capsule indentation by powder particles. A specific process (Aubert \& Duval proprietary) enables to remove this diffusion zone with some smoothening effect. 


\section{Mechanical properties}

Astroloy specimens with three surface conditions have been characterized:

- as-machined (Isoprec $\circledR$ reference condition)

- $\quad$ as acid leached (net-shape condition),

- $\quad$ as acid leached + surface treated (net-shape + surface treatment condition).

Tensile (room temperature, $650^{\circ} \mathrm{C}$ and $800^{\circ} \mathrm{C}$ ), creep $\left(650^{\circ} \mathrm{C}\right.$ and $800^{\circ} \mathrm{C}$ ) and $\mathrm{LCF}$ at $650^{\circ} \mathrm{C}$ under stress or strain control have been performed. Figures 6 to 9 show the obtained results.

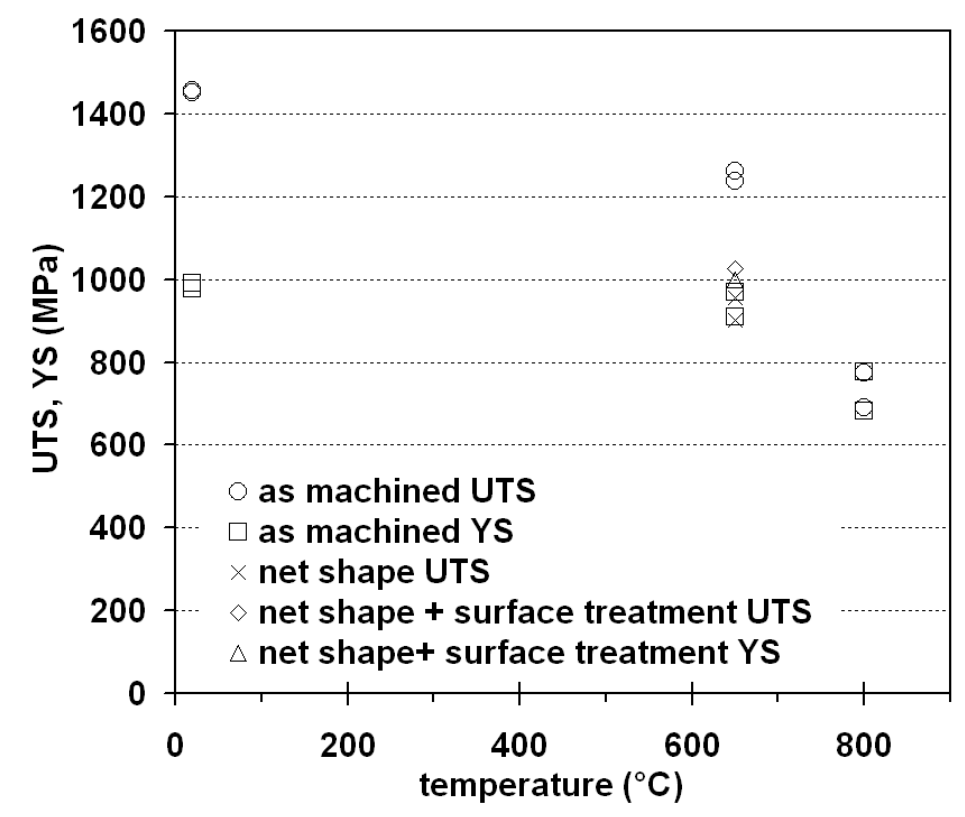

Figure 6: Tensile properties

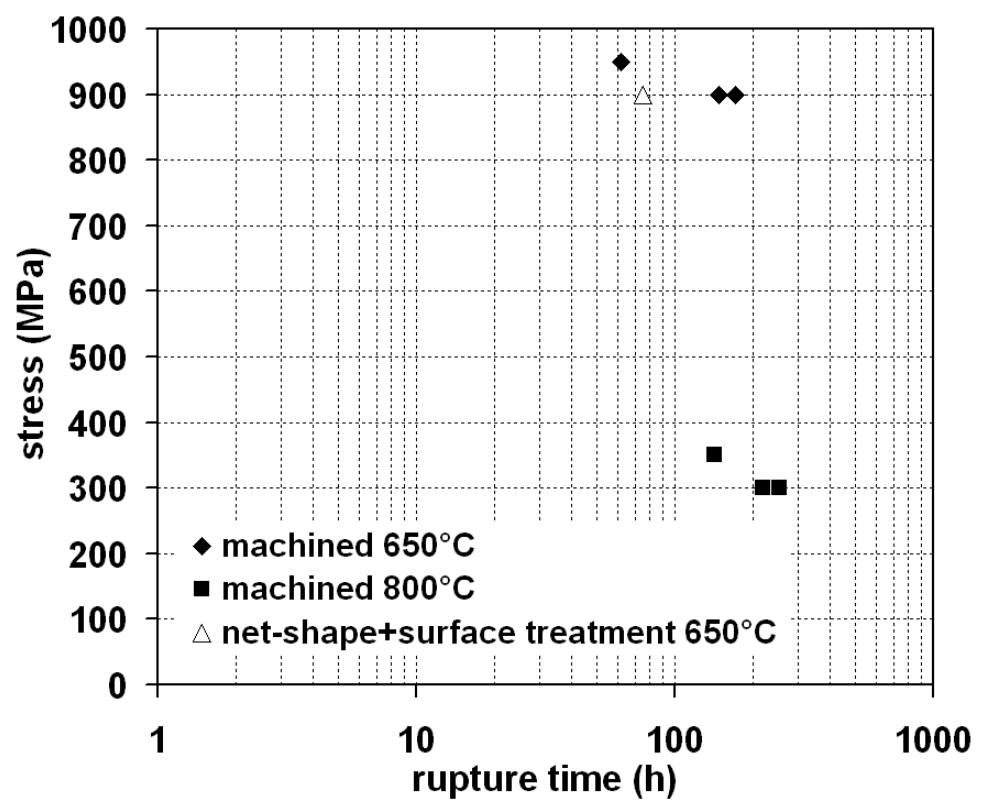

Figure 7: Creep rupture properties 


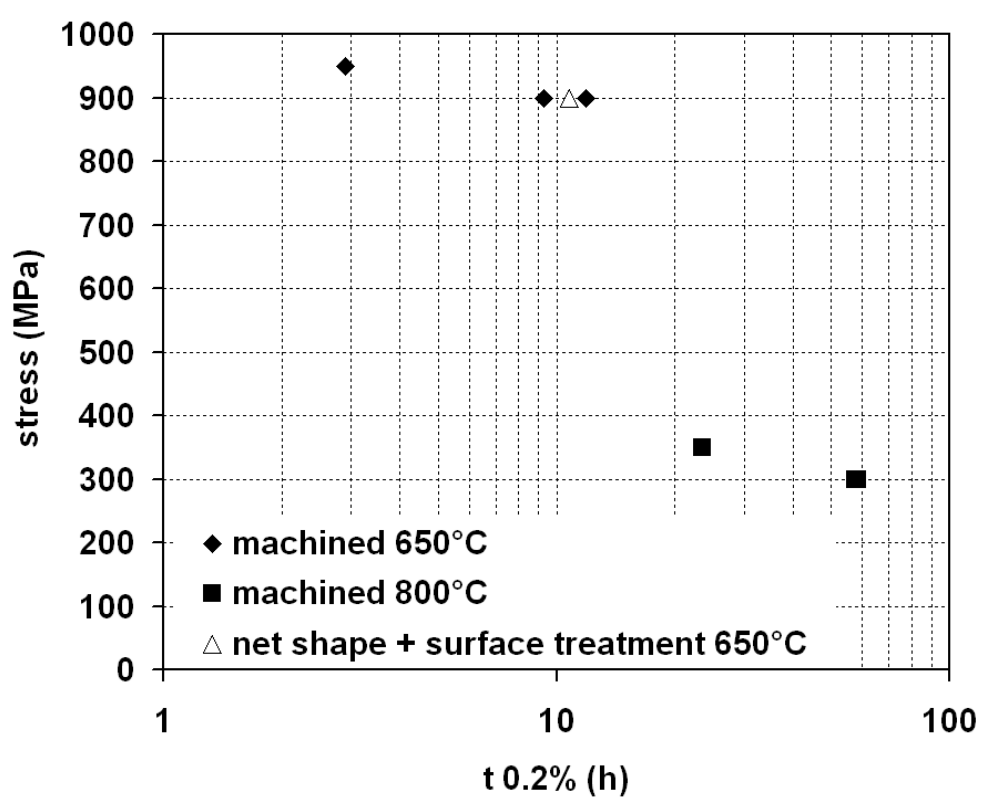

Figure 8: $0.2 \%$ creep elongation properties

For tensile and creep tests at $650^{\circ} \mathrm{C}$, the net-shape specimen failures occurred in the radii since their geometries were not precise enough. However, surface treated net-shape specimens exhibit a more ductile behaviour. The rupture strength revealed to be about $10 \%$ lower as compared to the reference as-machined condition. No difference was observed as regards $0.2 \%$ tensile yield strength or time for $0.2 \%$ creep elongation.

Strain controlled LCF tests were performed at $650^{\circ} \mathrm{C}(\mathrm{R} \varepsilon=0-0,5 \mathrm{~Hz})$. The reference asmachined data are slightly above the basic Astroloy and Waspaloy curves. For stress controlled LCF tests $\left(650^{\circ} \mathrm{C}-\mathrm{R} \sigma=0-0,5 \mathrm{~Hz}\right)$, a 30 to $40 \%$ resistance decrease is observed for net-shape specimens as compared to the as-machined reference ones. This is likely correlated to poor surface roughness since all the crack initiation sites are located at the surface of the specimens. After surface treatment, the LCF resistance is partially recovered and only a $20 \%$ decrease versus reference is observed.

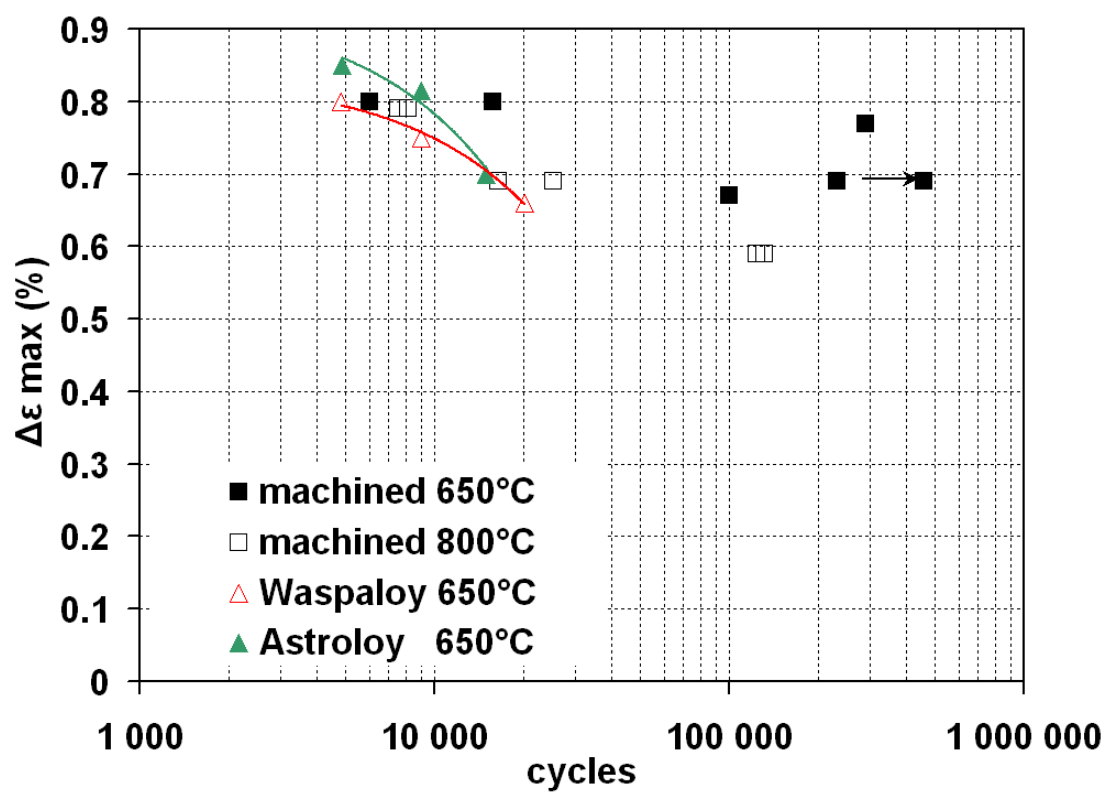

Figure 9: Low cycle fatigue at $650^{\circ} \mathrm{C}$ - Strain controlled $R \varepsilon=0$ 


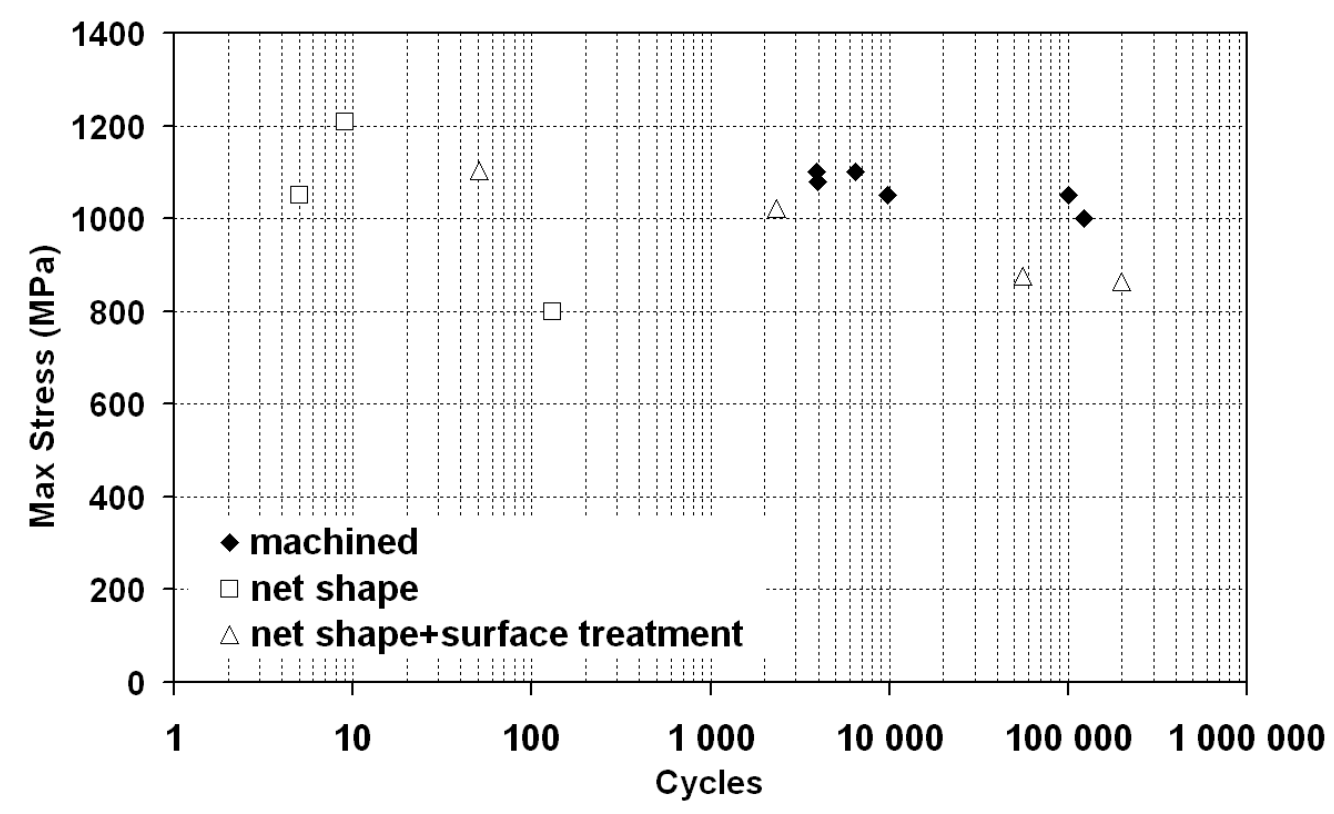

Figure 10 : Low cycle fatigue at $650^{\circ} \mathrm{C}$ - Stress controlled $\mathrm{R} \sigma=0$

\section{Conclusion}

Production of large or complex static parts for aero-engine or rocket-engine through Ni base alloys Powder Metallurgy Isoprec ${ }^{\circledR}$ process has been validated on two parts at full scale. This process enables the implementation of more temperature resistant alloys as compared to classical forged grades. Microstructural investigations and mechanical properties were assessed on representative laboratory specimens. In "as-machined" conditions, the mechanical properties are confirmed to be close to those measured on extruded + forged equivalent material. In as-decanned by acid leaching conditions, the mechanical properties and particularly ductility are significantly deteriorated. A specific surface treatment reduces the decrease to acceptable level for design but other studies would be necessary to quantify more precisely the detrimental effect and optimise the final surface treatment operation.

\section{References}

[1] G. Raisson: Evolution of PM Nickel base Superalloys Process and Products. Proceedings of Euro PM2007,Toulouse (France) October 15-17 ${ }^{\text {th }} 2007$. EPMA Editor.

[2] R. Baccino et al.: High performance and High Complexity Net-Shape Parts for Gas Turbine: The ISOPREC $®$ Powder Metallurgy Process. Research and Development in net-shape Manufacturing - Birmingham UK- March 24-26th, 1999.

[3] G. Raisson: Tailoring of Nickel- base Superalloys by HIPing. Proceedings of the 2005 International Conference on Hot Isostatic Pressing. Paris- May 22-25th 2005. SF2M Editor.

[4] D. Guichard et al.: Le procédé de mise en forme Isoprec ${ }^{\circledR}$. Journal de Physique IV, 10, PR4 (2000), p.39 